\title{
Education and growth with learning by doing
}

Citation for published version (APA):

Marconi, G., \& de Grip, A. (2014). Education and growth with learning by doing. ROA. ROA Research Memoranda No. 010 https://doi.org/10.26481/umaror.2014010

Document status and date:

Published: 01/01/2014

DOI:

10.26481/umaror.2014010

Document Version:

Publisher's PDF, also known as Version of record

\section{Please check the document version of this publication:}

- A submitted manuscript is the version of the article upon submission and before peer-review. There can be important differences between the submitted version and the official published version of record.

People interested in the research are advised to contact the author for the final version of the publication, or visit the DOI to the publisher's website.

- The final author version and the galley proof are versions of the publication after peer review.

- The final published version features the final layout of the paper including the volume, issue and page numbers.

Link to publication

\footnotetext{
General rights rights.

- You may freely distribute the URL identifying the publication in the public portal. please follow below link for the End User Agreement:

www.umlib.nl/taverne-license

Take down policy

If you believe that this document breaches copyright please contact us at:

repository@maastrichtuniversity.nl

providing details and we will investigate your claim.
}

Copyright and moral rights for the publications made accessible in the public portal are retained by the authors and/or other copyright owners and it is a condition of accessing publications that users recognise and abide by the legal requirements associated with these

- Users may download and print one copy of any publication from the public portal for the purpose of private study or research.

- You may not further distribute the material or use it for any profit-making activity or commercial gain

If the publication is distributed under the terms of Article $25 \mathrm{fa}$ of the Dutch Copyright Act, indicated by the "Taverne" license above, 


\section{Education and growth with learning by doing}

Gabriele Marconi

Andries de Grip

\section{ROA Research Memorandum}

ROA-RM-2014/10

Research Centre for Education and the Labour Market Maastricht University

P.O. Box 616, 6200 MD Maastricht, The Netherlands

$\mathrm{T}+31433883647 \mathrm{~F}+31433884914$

secretary-roa-sbe@maastrichtuniversity.nl www.roa.nl 


\title{
Education and growth with learning by doing
}

\author{
Gabriele Marconi \\ Andries de Grip
}

ROA-RM-2014/10*

September 2014

Research Centre for Education and the Labour Market

Maastricht University

P.O. Box 616, 6200 MD Maastricht, The Netherlands

$\mathrm{T}+31433883647 \mathrm{~F}+31433884914$

secretary-roa-sbe@maastrichtuniversity.nl

www.roa.nl

* The ROA Research Memorandum Series was created in order to make research results available for discussion, before those results are submitted for publication in journals. 


\begin{abstract}

\section{Education and growth with learning by doing**}

In this paper, we develop a general equilibrium overlapping generations model which is based on the view that education makes workers more productive by increasing their ability to learn from work experience, rather than providing skills that directly increase productivity. This assumption is discussed and compared with the dominant "Mincerian" view on the education-productivity relationship. One important implication of the model is that the enrolment rate to education has a negative effect on the GDP in the medium term and a positive effect in the long term. This could be an explanation for the weak empirical relationship between education and economic growth that has been found in the empirical macroeconomic literature. Conversely, for a given enrolment rate, the quality of education, as measured by workers' ability to learn, has a positive effect on the GDP both in the medium and in the long term.
\end{abstract}

JEL classification: J24; 011; 041

Keywords: education, learning-by-doing, productivity, economic growth, overlapping generations model

\author{
Gabriele Marconi \\ School of Business and Economics \\ Maastricht University \\ P.O. Box 616 \\ 6200 MD Maastricht \\ The Netherlands \\ g.marconi@maastrichtuniversity.nl
}

\author{
Andries de Grip \\ Maastricht University \\ ROA \\ P.O. Box 616 \\ NL-6200 MD Maastricht \\ The Netherlands \\ a.degrip@maastrichtuniversity.nl \\ and IZA, Bonn
}

\footnotetext{
** We thank Jo Ritzen, Adriaan van Zon, Roxanne Korthals, David de la Croix and the participants at the IRES Macro Lunch Seminar in Louvain-la-Neuve (BE, 26/03/2013), the 2012 Conference of the Scottish Economics Society in Perth (UK, 16-18/04/2012), the 2012 Spring meeting of Young Economists in Mannheim (DE, 26-28/04/2012), and the DUHR Seminar in Maastricht (NL, 09/05/2012), for helpful comments and suggestions.
} 


\section{Introduction}

Education is expected to be positively related to economic outcomes at both the individual and aggregate level. However, in the macroeconomic literature, studies estimating the relationship between education and economic growth have found mixed results. In particular, when regressing changes in aggregate output on changes in the average years of education in different countries, macroeconomists have often found insignificant coefficients, sometimes with negative signs. These puzzling results led economists to put forward a number of explanations, from the failure of the assumptions on which traditional growth theories are based, to bad data quality (Benhabib and Spiegel, 2005; Krueger and Lindahl, 2001; Pritchett, 2006). In contrast, the quality of education appears to be correlated with economic growth (Hanushek and Woessmann, 2012). Hence, an explanation for the insignificant relationship between years of education and economic growth would be more convincing if it was consistent with a positive relationship between quality of education and growth.

This paper offers an alternative explanation for the unexpected results found in the educationgrowth literature, by developing and simulating a general equilibrium model. Our model is based on the view that more education makes workers more productive by increasing their ability to learn from experience, rather than by providing competencies which are directly usable in production. This is consistent with studies in labour and development economics, which state that the main role of initial education is not providing individuals with competences directly usable in production, but by teaching them how to learn from changes in technology (Rosenzweig, 1995; Welch, 1970). Similarly, we assume that an education of better quality does not contribute to graduates' productivity immediately after leaving education but instead increases the ability of individuals to learn from work experience. As a result, at the completion of their study programme, graduates may be less productive than their peers, who accumulated work experience instead of studying. However, graduates are expected to learn faster on the job which will make them more productive than nongraduates during the later stages of their career. At an aggregate level, this suggests that increasing the enrolment rate to education has a negative medium-term effect on total (absolute) output: investing more resources in education implies diverting resources away from production and reducing work experience of those who stay in school longer. However, the long-term effect of an increase in the enrolment rate to education on aggregate output is expected to be positive, because educated workers are more productive in the long run.

Moreover, the model we develop takes the quality of education into account. Quality of education is assumed to be a set of characteristics of the educational system that increases the ability of 
graduates to learn from work experience. The better the quality of the education, the faster educated workers catch up with the productivity of their peers. As a consequence of an increase of the level of education of the workforce, a country providing higher quality education will experience less output loss in the medium term, and a faster output growth in the long term than a country providing lower quality education.

A direct negative effect of the amount of education on total aggregate output, due to a reduction of the workforce, is already included in current theoretical frameworks (e.g. Lucas, 1988). However, in this paper we focus on the effect of educating a cohort on economic growth after graduation. To avoid confusion between the two types of effect, we avoid using the term "short-term effect" but refer to the effect of education on economic growth immediately after graduation as the "mediumterm" effect of education, and use the term "long-term" effect to indicate the effect of education on economic growth a longer time after graduation.

This distinction between the medium and long term effects of an increase in the enrolment rate to education has important implications for policy makers. Investing in the quantity of education (as opposed to the quality of education) can be painful for short-sighted governments, which feel urged to boost economic growth quickly at times when the economy faces stagnation. However, increasing the enrolment rate to education remains a necessary investment for attaining sustainable growth in the long term.

This paper contributes to the literature on the relationship between educational investment and economic growth by specifying a model on the accumulation of human capital, which is similar in nature to a learning curve. We will discuss this model and explore its macroeconomic implications. We show that it offers a possible explanation for the mixed results of the empirical literature on the relationship between education and growth.

The theoretical model represents an economy with three overlapping generations, in which individuals choose their consumption and decide whether or not to attend education. Individual human capital is aggregated at the economy level and enters a Cobb-Douglas aggregate production function. In the medium term, the loss of work experience induced by enrolling in education translates into a lower level of human capital and, consequently, into a lower level of total aggregate output (which in the model is proportional to per capita output, as the population size is constant). In equilibrium, the effect of rising enrolment rates is the sum of the medium-term negative effect and the long-term positive effect of education on productivity. This implies that more investments in 
education do not necessarily lead to more economic growth in the medium term. The implications of the model are illustrated by a numerical simulation.

Our model also contributes to the literature on learning by doing and economic growth. This literature has explored several implications of learning by doing at the macroeconomic level with respect to total factor productivity (Arrow, 1962), population growth (Simon and Steinmann, 1984), choice of technology (Jovanovic and Nyarko, 1996), and international trade (Torvik, 2001). However, one implication has not fully been investigated yet: if the majority of productivity improvement in an economy particularly stems from learning by doing, then it is necessary to re-consider the role of education for economic growth. The model we develop in this paper fills this gap.

The model is obviously related to the literature on overlapping generations model (see de la Croix and Michel, 2002 for a review). We postulate an economy in which there are three generations: the young, which individuals choose whether to go to school or to work; and the other two, which individuals work with different productivity.

Notice that, in our model, the third period of the life of individuals is needed because it allows to split the work career of educated individuals into two parts: one in which educated individuals are unproductive because they have no work experience; and one in which they are productive, because they have already accumulated some work experience. This differentiates our model from other three-period overlapping generations models, which normally include a third period of life to explore problems related to retirement. Our model also differs from the literature on individual investments in education and economic growth, as we model the educational enrolment rate, instead of the amount of time individuals invest in education. Furthermore, opposed to other studies in the macroeconomic learning-by-doing literature, we assume technological change to be exogenous.

The remainder of the paper is organised as follows. Section 2 discusses the relationship between learning by doing, education and productivity at the micro-economic level. Section 3 discusses the current education-growth puzzle. Section 4 describes the assumptions of our model, and Section 5 derives the equilibrium and the theoretical implications of our model. Section 6 presents the results of a simulation study under alternative educational policies. Section 7 draws some conclusions. 


\section{Learning-by-doing and Mincerian effects of education}

The macroeconomic literature on learning by doing and economic growth suggests that productivity improvements in an economy are largely due to workers' learning from experience. In this framework, it is not straightforward to think of the role of education for production. This paper suggests that the most important channel by which education affects workers' productivity is by enhancing individuals' ability to learn from experience. This implies that young graduates are less productive than their unskilled peers in the same age group as the latter have more work experience. Figure 1 illustrates this idea. It depicts productivity curves for educated and unskilled workers under the extreme assumption that education affects productivity only by enhancing the ability for learning by doing. This assumption will be the basis of the theoretical model presented in Section 4. At the beginning of their working career, both un-skilled and educated workers start off unproductively. This moment in the career of workers can be thought of as an unpaid internship, or as a phase in which the employer is investing in the young worker by paying her more than her marginal productivity. By the time educated workers complete their education, unskilled workers of their cohort have already accumulated some work experience. Hence, Figure 1 shows that at the beginning of their working careers educated workers are less productive than those of the same age without education but some years of work experience. ${ }^{1}$ However, the slope of their age-productivity curve is much steeper, which makes them more productive than the unskilled workers in their age group during the second part of their careers.

This view of the effect of education on productivity is opposed to the "Mincerian" effect of education, i.e. a proportional effect of education on productivity which remains constant during the working career. Mincer (1974) provided some informal evidence supporting the hypothesis of a proportional effect of education on wages. Together with the neoclassical assumption that wage equals marginal productivity, this has led many economists to assume that the effect of education on productivity is roughly constant over time. However, this hypothesis has been rejected by Heckman et al. (2006) using U.S. census data of the last three decades. Furthermore, studies indicating that technological change affects returns on education (e.g. Rosenzweig, 1995; Welch, 1970) seem to confirm that learning by doing, and in particular the ability to deal with new technologies, are important determinants of labour productivity.

1. Some casual evidence indicating that the initial productivity of graduates could be very limited at the beginning of their career is given by the popularity of (often unpaid) internships in many European countries. For example, in 2010 in Italy around $52 \%$ of recent graduates embarked on an internship or apprenticeship (Almalaurea, 2011). 
If there was precise data on convincing measures of productivity as well of the level and quality of education for comparable individuals, it would not be difficult to determine whether the most important channel through which education affects productivity is related to the "Mincerian" or learning-by-doing effect. However, as there is a lack of such data, economists have to rely on data on wages. Data on wages could show whether there is a "Mincerian" or a learning-by-doing effect of education on productivity under two conditions. First, that the individuals choosing different levels of education do on average not differ in terms of their innate abilities and second, that wage equals marginal productivity at any point of a worker's career.

Figure 1 Individual productivity curve by level of education (education or no education) under the hypothesis that education contributes to productivity only by increasing the ability to learn by doing

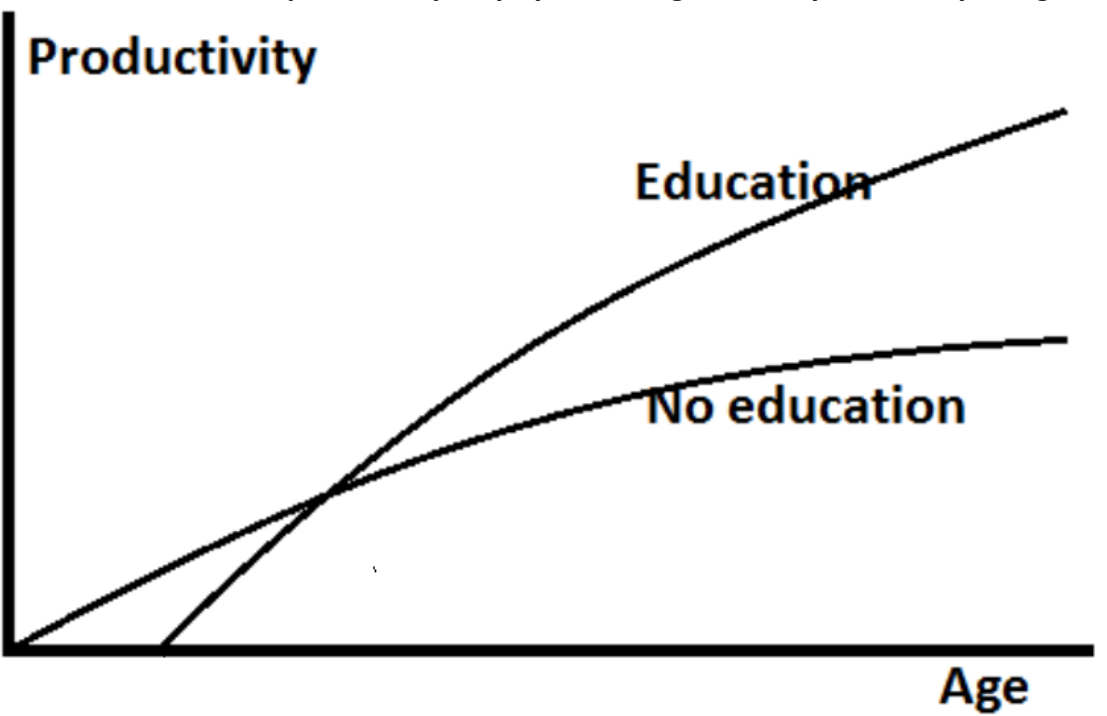

It is difficult to assess whether these two conditions are satisfied. First, some individuals are more likely to study and to earn more on the labour market because of their innate abilities. Second, microeconomic theory gives different predictions about the relationship between productivity and wages for different stages of the career of workers. Well-known models predicting that differences in wages do not correspond to differences in productivity include models on incentive-compatible wages (Lazear, 1979) and efficiency wages (Yellen, 1984).

Detailed administrative data have recently opened the opportunity to explore the wage-productivity relationship empirically, but reaching reliable conclusions seems to be extremely difficult (Cardoso et al., 2011; Dostie, 2011; Hellerstein and Neumark, 1995). At the current state of knowledge, it is difficult to infer from microeconomic data whether wages are higher, lower or equal to productivity in the first years of the careers of graduates. As a result, it is difficult to reach conclusions on which role education plays for individual productivity in the early and later stages of the life course from microeconomic data. 
At the end of our discussion on the effect of education on productivity, it should be noted that, for a negative medium-term effect of education on productivity to exist, it is not necessary to assume that productivity only increases with learning by doing. If education had a "Mincerian" effect on workers' productivity, the medium-term effect of education on productivity would still be negative as long as this "Mincerian" effect is not large enough to compensate for the years of lost experience in the labour market.

\section{The education-growth puzzle}

Following the theoretical model by Lucas (1988), many studies in the macroeconomic literature, have assumed that the effect of education on productivity comes from a constant productivity premium. ${ }^{2}$ This implies that investments in education translate into productivity immediately. However, a large number of macroeconomic studies have estimated the relationship between education and economic growth by regressing changes in (the logarithm of) GDP on changes in measures of human capital (e.g., the average number of years of education across the working population) and physical capital for different countries (Benhabib and Spiegel, 1994, 2005; Krueger and Lindahl, 2001; Pritchett, 2001, 2006). The results obtained in these studies (insignificant coefficients, sometimes with negative signs) challenged the belief that education is positively related to economic growth. Studies at state level, conducted for the US and using different methodologies, led to similar results (see Curs et al., 2011, for a review). This seems to confirm the "failure of education as an economic strategy" that Thurow (1982) described more than three decades ago. These results came as a surprise, especially since microeconomic empirical work found high returns to education: usually around 6-10\% all over the world (Psacharopoulos and Patrinos, 2004). The unexpected results with regard to the sign and significance of the coefficients led economists to put forward a number of explanations. In this section, four of these explanations are discussed in more detail: the need for endogenous growth models to capture the growth process (Benhabib and Spiegel, 1994, 2005); an actual negative relationship due to rent-seeking (Pritchett, 2006); differences in the quality of education across countries (Hanushek and Woessman, 2012), and poor data quality (Krueger and Lindahl, 2001).

2. Although most studies make the constant-productivity-premium assumption, there are exceptions. For example, van Zon and Antonietti (2005) assume productivity to be determined by formal education as well as on-the-job training. They assume that workers are not productive without on-the-job learning, and the effect of schooling is revealed later on, when the worker acquires on-the-job training. Several papers found evidence supporting the idea that education facilitates learning through on-the-job training, especially in the presence of technological change (see e.g. Brunello, 2001; Frazis and Herz, 1995). Although this paper focuses on the role of education in facilitating learning by doing, the results can be generalised without difficulty to all forms of learning on the job, including on-the-job training. 
Benhabib and Spiegel (1994) measure the human capital stock by the average number of years of education across the working population, i.e. a linear specification of the human capital stock. They estimate a Cobb-Douglas aggregate production function (in logarithms) both in levels and in growth rates (i.e., first differences 1965-1985). Human capital stock is found to be significantly and positively related to growth in levels, but not in first differences. To explain the results, the authors propose an endogenous growth model based on Nelson and Phelps (1966), in which the stock of human capital within a country contributes to growth by increasing workers' ability to either imitate the technology already in place elsewhere or innovate. However, as noticed by Pritchett (2001), the fact that the stock of human capital affects economic growth still implies that changes in human capital should affect growth positively (by increasing the human capital stock).

Pritchett $(2001,2006)$ offers a number of explanations for the education-growth puzzle, one of which is the omission of the quality of education from growth regressions. Remarkably, the quality of education appears to be associated with income growth. Hanushek and Woessman (2012) show that a country's students' cognitive skills and subsequent economic growth are strongly correlated. They suggest that the quality of education, defined as a set of institutional characteristics of the educational system which increase the cognitive performance of students, affects economic growth by increasing the cognitive skills of the population. However, this cannot explain the educationgrowth puzzle: the fact that the quality of education matters seems to be at odds with the suggestion that the quantity of education is irrelevant.

Prichett also mentions rent seeking as a possible explanation of the education-growth puzzle. Economic theory generally assumes perfectly competitive markets, but the extent to which this assumption approximates reality varies from country to country. In some economies, additional education could particularly increase the ability of individuals to extract a rent from the economic environment, which will slow down economic growth. This explanation is investigated empirically by Rogers (2008), who finds some support for it. However, if individuals who received more years of education contribute negatively to GDP because they are able to extract a rent from the economic system, it would follow that individuals who received education of higher quality should also contribute negatively to GDP for the same reason. Hence, quality of education should also be weakly or negatively associated with economic growth, which does not appear to be the case.

Probably the most cited reason to explain the education-growth puzzle is poor data quality (Krueger and Lindahl, 2001). The fact that there is considerable noise in the macroeconomic data used in the literature, however, does not rule out that the empirical findings adequately represent reality. Pritchett (2001) makes this point by showing that the insignificant coefficients obtained when 
regressing growth on education can be transformed by some algebraic manipulation into a significant, negative relationship between education and the estimated total factor productivity.

There are a number of studies which find evidence of a positive relationship between education and growth. Cohen and Soto (2007) show results based on new series, which they produce and claim to be of better quality than previous series. They obtain results in line with expectations for one of the empirical models that they estimate. Temple (1999) finds a positive relationship between changes in education and growth after removing outliers. It is important to notice that these two papers use changes over 20-year and 30-year periods in education and GDP suggesting that, it is only in the long term that the relationship between education and economic growth is positive.

Building on these findings, we argue that the education-growth puzzle can be explained by the missspecification of the relationship between education and productivity. Assuming that learning by doing is the driver of individual productivity, young graduates are expected to be less productive than the unskilled peers in their cohort who have accumulated work experience instead of studying. However, graduates are expected to learn faster on the job and to be more productive than unskilled workers during the later stages of their career. At an aggregate level, this suggests that a rise in the enrolment rate to education has a negative medium-term effect on the total output: investing more resources in education implies diverting resources away from production as well as reducing work experience for those who participate in education. Conversely, the long-term effect of a rise in the enrolment rate on the total output is expected to be positive because educated workers will be more productive in the long run, after accumulating work experience.

\section{The model}

The model we develop in this paper assumes a one-sector economy with three overlapping generations of workers, living for three periods. Every worker can work for two or three periods, so that every period can be thought of as corresponding to about 15 years. In the remainder of the paper, we will refer to "medium-term effect" to indicate the effect of a variable observed at time $t$ on another variable observed in the next period (time $t+1$ ), whereas we will refer to "long-term effect" as the effect of a variable observed at time $t$ on another variable observed after two periods (time $t+2)$.

The population consists of three cohorts of size 1, composed of identical individuals. Individuals decide whether to study or to work in the first period, and works necessarily in the second and third period of their life. Education provides no utility or disutility to individuals. Individuals are 
distinguished by an integer number $t$ indicating their birth year and by an index $i=\{e, u\}$ indicating their education status (i.e. educated $(e)$ or unskilled $(u)$ ).

The total value of the utility enjoyed by an individual born in year $t$ and belonging to the education category $i$ throughout his life, $U_{t}{ }^{i}$, is given by:

(1) $U_{t}^{i}=\ln c_{0, t}^{i}+\beta \ln c_{1, t}^{i}+\beta^{2} \ln c_{2, t}^{i}$

Where $c_{g, t}^{i}$ denotes the consumption of the individual at age $g$ (or, to use an equivalent expression, at time $t+g$ ) with $g$ as an index of age which takes values 0 in the first period of life of an individual, 1 in the second period, and 2 in the third period; and the parameter $\beta$ is the rate of patience of individuals. It is assumed that individuals do not decide on their own consumption in the first period. As a result, the first term of the sum is constant from the individual point of view, and does not enter his maximisation problem. This assumption is quite common in the 3-periods-of-life overlapping

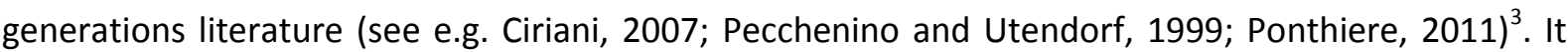
could be interpreted as assuming that the consumption of young individuals is included in the consumption of altruistic parents, i.e. the older generation ${ }^{4}$.

We further assume that individuals consume all their wealth before the end of the last period of their life. They may borrow or lend part of their income to other individuals, but under the constraint that these transfers are paid back so that at the end of their life there is no positive or negative asset left. Given that individuals purchase consumption goods only during the second and third period of their life, the following budget constraint must be satisfied:

(2) $R_{t+2} c_{1, t}^{i}+c_{2, t}^{i}=V_{t}^{i}$

Where $R_{t+2}$ is equal to 1 plus the rate of return to the savings of period $t+1$, and $V_{t}^{i}$ is the value of the income earned by an individual born at time $t$ and belonging to the educational category $i$ over the three periods of the individual's life. $V_{t}{ }^{i}$ is evaluated at the third period because this simplifies the notation in the remainder of the paper.

3. This assumption ensures convergence of the model to a steady state. Convergence to the steady state is particularly difficult to achieve otherwise, because individuals work in the last period in this model.

4. Following this interpretation, one could consider modifying the individuals' utility function, to capture the additional utility given by their children's consumption. Supposing that all individuals are parents in the third period of their life, their utility function could be expressed as:

$$
U_{t}^{i}=\ln c_{0, t}^{i}+\rho \ln c_{1, t}^{i}+\rho \beta \ln c_{2, t}^{i}
$$

Where $\rho$ is the discount parameter; and $\beta=\rho \theta$, where $\theta>1$ represents the extra utility enjoyed by altruistic parents because the consumption goods that they purchase are consumed also by their children. Maximising this utility function gives the identical results as maximising Equation (1). 
We model the learning-by-doing effect of education in a human capital accumulation equation which is exponential in work experience. This function is expressed in its discrete-time version (Equation (3)) and in its continuous-time version (Equations Error! Reference source not found. and Error! Reference source not found.). The productivity at age $g$ of an individual born at time $t$ and belonging to the educational category $i$ is given by:

(3) $h_{g, t}^{i}=\left[\sum_{j=0}^{g} l_{j, t}^{i}\left(a A_{t+j}\right)^{\varphi}\right]^{\sigma+\gamma s}$

Where $l_{j, t}$ is a binary variable equal to 1 if the individual worked at age $j$, and 0 otherwise (with $j=0, \ldots, g) ; a$ is a scalar; $A_{t+j}$ is an index representing the technology available at time $t+j$ (this is the same index as in Equation (6)); and $s$ is a binary variable representing the quantity of education, and it is equal to 1 if the individual has undertaken education, and 0 otherwise; $\varphi, \sigma$ and $\gamma$ are parameters of the model.

The term in the square brackets in Equation (3) can be interpreted as accumulated work experience. Indeed, if $\varphi=0$, that term is equal to the number of time periods spent working. However, if $\varphi>0$, then there is an adjustment for the technological level of the work environment: a given amount of time spent working in a more technologically-advanced environment allows the worker to accumulate more human capital than the same amount spent in a less technologically-advanced environment. Hence, the parameter $\varphi$ is a parameter related to the technological environment. If $\varphi=0$, then the technological environment does not accelerate learning by doing. The case $\varphi>0$, implying that learning is faster in technologically advanced countries for a given level of education, appears more realistic on the basis of the discussion on migration of skilled workers. ${ }^{5} \sigma+\gamma s$ is the elasticity of productivity with respect to work experience. $\sigma$ is the base rate of learning by doing; it represents how fast individuals without formal education learn on the job. The parameter $\gamma$ represents the quality of education. The higher it is, the more education enhances learning by doing. In other words, the productivity of workers who received good-quality education increases faster than the productivity of workers who received education of lower quality. As mentioned, we assume that $\gamma>0$, so that education - although it has no direct effect on productivity - increases the speed of learning on the job.

5. For example, "brain circulation" (temporary migration of skilled workers from developing to developed countries) is considered to be beneficial to the sending country, because the workers that temporarily migrate to technologically advanced economies come back with an increased level of human capital (Solimano, 2002). Saxenian (2005) provides suggestive evidence from a case study involving workers migrating from developing countries to Sylicon valley. 
Figure 2 Productivity and work situation for unskilled and educated individuals throughout their lives

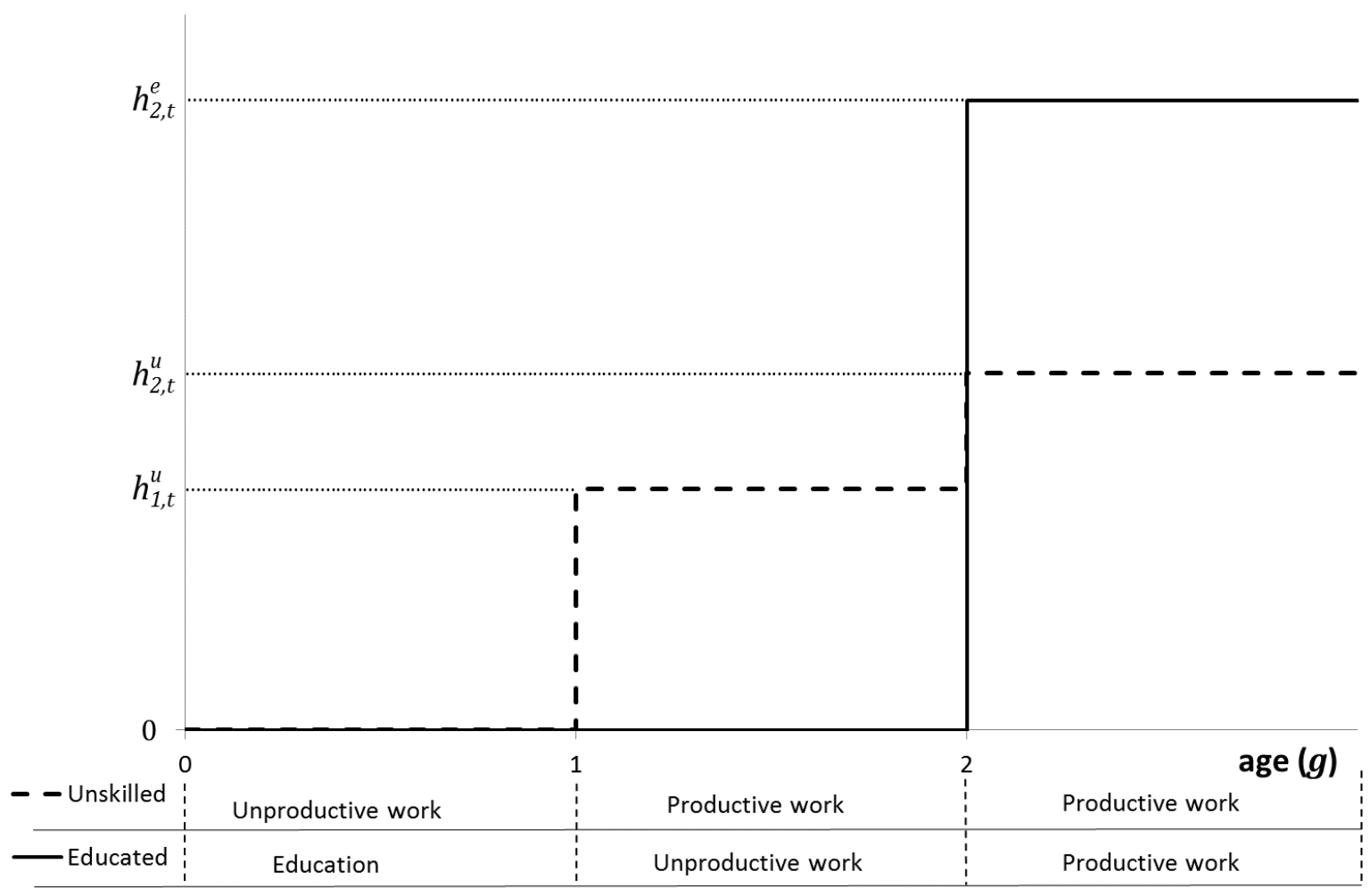

Figure 2 shows a hypothetical age-productivity profile for both educated and unskilled workers. Under the assumption that salary equals marginal productivity, this coincides with their age-wage profile. Productivity is on the vertical axis. The values for $h_{g, t}^{u}$ and $h_{g, t}$ denote the productivity at time $t+g$ of unskilled and educated individuals who are born at time $t$, respectively. These values are the same as for the individuals born in period 3 in the baseline simulation of Section 6 . Unskilled individuals start working during the first period of their life $(t)$, but they are assumed to be not productive because they lack work experience. In the second period of their life, unskilled individuals are already productive, and their productivity is equal to $h_{1, t}^{u_{1}}$. Their productivity peaks during the third period of their life, when it is equal to $h^{u} u_{2, t}$ because they have accumulated two periods of work experience. Educated individuals are in education at time $t$, so that they start working in the second period of their life $(t+1)$. Similarly to unskilled workers, they are not productive in their first period at work. However, they learn quickly from experience, and their third-period productivity $\left(h_{2, t}\right)$ is higher than that of unskilled workers. Notice that educated workers are only productive in the third period of their life, so that the individuals' choice whether to undertake education is determined by a tradeoff between foregone salary in the second period and the possibility to enjoy a higher salary in the third period of their life. This is the reason why individuals live for three periods and work in the third period of their life, differing from the majority of papers in the overlapping generations' literature. 
Following e.g. de la Croix (2001), we assume that effective units of human capital are perfect substitutes. Hence, the value of individual lifetime earnings coincide with the amount of human capital that they can deploy, multiplied by the marginal productivity of a unit of human capital, $\omega_{t}$. Hence, for educated and unskilled individuals, the life-time value of income is equal to, respectively:

(4) $V_{t}^{e}=\omega_{t+2} \cdot h_{2, t}^{e}$

(5) $V_{t}^{n}=R_{t+2} \cdot \omega_{t+1} \cdot h_{1, t}^{n}+\omega_{t+2} \cdot h_{2, t}^{n}$

Only one type of good $(Y)$ is produced in the economy, used for both consumption and investments. Production at the firm's level is a Cobb-Douglas function, implying that the aggregate output at time $t\left(Y_{t}\right)$ is also given by a Cobb-Douglas function with aggregate stocks of physical $\left(K_{t}\right)$ and human capital $\left(H_{t}\right)$ as factors of production,

(6) $Y_{t}=\left(A_{t} H_{t}\right)^{1-\alpha} K_{t}^{\alpha}$

Where $A_{t}>0$, representing the technology available, is assumed to grow at a constant, exogenous rate equal to $\mu-1$. Physical capital is assumed to fully depreciate in every period. This is a common assumption in the overlapping generations literature where one period often corresponds with 15 to 25 years (see e.g. De la Croix and Michel, 2002). With capital market clearing (savings equal investments), this implies:

(7) $K_{t+1}=I_{t}=Y_{t}-C_{t}$

Where $I_{t}$ is investment and $C_{t}$ is aggregate consumption. Aggregate human capital is given by the sum of the human capital of all individuals in the economy:

(8) $H_{t}=\left(1-q_{t-1}\right) \cdot h_{1, t-1}^{n}+\left(1-q_{t-2}\right) \cdot h_{2, t-2}^{n}+q_{t-2} \cdot h_{2, t-2}^{e}$

Where $q_{t-g}$ is the fraction of individuals born at time $t-g$ who enrol in education (enrolment rate). Notice that the quantity of education in a cohort (represented by the enrolment rate) has a negative medium-term effect on aggregate human capital, as indicated by the negative sign on $q_{t-1 .}{ }^{6}$

Finally, it is useful to define the ratio of physical to human capital $\left(k_{t}\right)$ as:

(9) $k_{t} \equiv \frac{K_{t}}{A_{t} \cdot H_{t}}$

6. As mentioned above, we qualify the effect of education on another variable observed in the next period as the "medium-term effect" 
In this model, there is no cost of education. Hence, many institutional features of the educational system are excluded from the analysis.

Before moving on to the static and dynamic analysis of the model, it is useful to consider the continuous-time version of the individual human capital accumulation equation. Omitting the superscript denoting the educational category of the individual, Equation (3) can be re-written as:

$$
\begin{aligned}
h_{g, t} & =x_{g, t}{ }^{\sigma+\gamma s} \\
x_{g, t} & =\int_{t}^{t+g} l_{j}\left[a A_{t+j}\right]^{\varphi} \mathrm{d} j
\end{aligned}
$$

Where $x_{g, t}$ is work experience at time $t+g$, corrected for the influence of the technological environment; and $s$ is the quantity of education. The two previous equations, which amount to a decomposition of the continuous-time equivalent of Equation (3), are closely related with equations drawn from the economic literature. Equation Error! Reference source not found. is the inverse of the well-known learning curve (e.g. Alchian, 1963; Arrow, 1962). If labour productivity is replaced with labour input per unit of output, then Equation (10) takes the classic shape of a learning curve with a rate of learning equal to $\sigma+\gamma s$.

A parallel can also be made between Equation (12) and Jones' (1995) classical "R\&D equation". This can be seen by differentiating Equation (11) with respect to time (or, more precisely, with respect to age), which yields:

$$
\frac{\partial x_{g, t}^{i}}{\partial g}=l_{g}\left(a A_{t+g}\right)^{\varphi}
$$

Both this equation and Jones' (1995) "R\&D equation" represent an endogenous source of productivity increase over time which is alternative to physical capital accumulation. The increase in productivity depends on the level of technology and on the amount of human resources devoted to production. It should be noted that Jones (1995) here refers to human resources devoted to innovation. However, whereas in Jones' (1995) semi-endogenous model, the endogenous source of change in productivity is the increase of product differentiation, in the model of this paper it is the accumulation of work experience. In this respect, the model we developed differs from other studies 
in the learning-by-doing growth literature (Arrow, 1962; e.g. Jovanovic and Nyarko, 1996; Simon and Steinmann, 1984), which considers technical change endogenous. ${ }^{7}$

\section{Theoretical implications}

The economy described in Section 4 has three basic types of equilibrium. In the first one, investing time in education does not pay off for the individual (i.e. the lifetime value of income is higher for unskilled individuals than for those educated), so that the enrolment rate is equal to 0 . We label this equilibrium the "no education regime". In the second one, the lifetime value of income is equal for unskilled and educated individuals, so that the enrolment rate is between 0 and 1 . This type of equilibrium will be labelled the "partial education regime". In the third type, which we label the "universal education regime", the returns to education are always positive, so that the enrolment rate is equal to 1 . If the economy starts from of a low level of $k_{t}$, and $\varphi>0$ (so that the wage premium is increasing over time), then the economy passes through all three stages, starting from the first (no education), and ending up in the third (universal education).

In this section, the second and third type of equilibrium are analysed. We will show that, given the assumptions on the effect of education on productivity, the relationship between enrolments and aggregate output or growth is not necessarily positive in the medium term. First, in a static context, enrolling more students means decreasing aggregate output in the medium run. Second, in a dynamic equilibrium, a relatively high growth in enrolment rates does not necessarily lead to a relatively high rate of economic growth. The reason is that the effect of education on growth is the sum of the negative medium-term effect and the positive long-term effect. We also show that the quality of education has a positive effect on aggregate output and on the steady-state growth rate.

\section{Static analysis}

The negative relationship, at a given point in time, between the enrolment rate and productivity in the next period translates into a negative relationship between the enrolment rate and total output in the medium term. Conversely, the positive relationship between enrolment rate at time $t$ and productivity at time $t+2$ causes a long-term positive relationship between education and output. Consider a snap-shot analysis of an economy (not necessarily in equilibrium) taken at time $t$ with a given stock of physical capital $\left(\bar{K}_{t}\right)$, enrolment rates $\left(\bar{q}_{t-1}>0\right.$ and $\left.\bar{q}_{t-2}>0\right)$ and, consequently, human

7. Some studies on growth and learning by doing have not modelled technological change per se, but have only modelled productivity (or human capital), which is endogenous, because it depends on past work experience (e.g. Torvik, 2001). 
capital stock $\left(H_{t}\right)^{8}$. According to Equations (6) and (8), the first derivatives of $Y_{t}$ with respect to the different enrolment rates are equal to:

$$
\begin{gathered}
\frac{\partial Y_{t}}{\partial \bar{q}_{t-1}}=-(1-\alpha) k_{t}^{\alpha}\left(a A_{t-1}\right)^{\sigma \varphi}<0 \\
\frac{\partial Y_{t}}{\partial \bar{q}_{t-2}}=(1-\alpha) k_{t}^{\alpha}\left(a A_{t-2}\right)^{\sigma \varphi} d_{t-1}>0
\end{gathered}
$$

where

$$
d_{t-1} \equiv \frac{h_{2, t-1}^{u}-h_{2, t-1}^{e}}{h_{1, t-1}^{u}}=\mu^{\varphi \sigma}\left(a A_{t}\right)^{\varphi \gamma}-\left(1+\mu^{\varphi}\right)^{\sigma}
$$

Provided that the human capital endowment of educated workers is higher than that of unskilled workers in the last period of life, which is the minimal condition required for the returns to education to be positive, the enrolment rate has a positive effect on aggregate output in the long term. However, in the medium run, the relationship is negative because in the early stage of their careers, educated workers are less productive than their unskilled peers. Differentiating $Y_{t}$ with respect to $\gamma$ yields:

$$
\frac{\partial Y_{t}}{\partial \gamma}=(1-\alpha) k_{t}^{\alpha} \cdot\left(a A_{t-1}\right)^{\varphi(\sigma+\gamma)} \cdot \ln \left(a A_{t-1}\right) \cdot \bar{q}_{t-2}>0
$$

This implies that the effect of an increase in the quality of education on the total output in the next two periods is positive. Notice that the sign of the expressions in Equations (13) and (15) does not change if output per capita is used instead of total output, as the population is assumed to be constant.

\section{Dynamic analysis}

We define the equilibrium of the economy as a path of the variables $k_{t}, q_{t}, R_{t}, \omega_{t}, c_{1, t}^{i_{1}}, c_{2, t}^{i}(i=u, e)$ and $I_{t}$ for every period $t=\ldots,-1,0,+1, \ldots$, in which individuals are maximising their utility, each firm is maximising its profits, and markets of physical and human capital clear. All paths for the other variables $Y_{t}, C_{t}, S_{t}, K_{t}, H_{t}, V_{t}{ }^{i}$ are determined by the formulas outlined above. In this section, we focus on those types of equilibrium in which the enrolment rate is positive. We will start by discussing the partial education regime, and then turn to the discussion of the universal education regime.

8. In the following, the notation $\bar{X}_{t}$ means that the value of variable $X$ at time $t$ is a given value (input of the model). The notation $X_{t}$ means that the value of variable $X$ at time $t$ is computed using the formulas outlined above. 
In equilibrium a number of conditions must be satisfied. The rental prices for physical and human capital should be equal to their marginal productivity due to perfect competition. Adding full depreciation for physical capital, the following equations must hold:

$$
\begin{aligned}
& R_{t}=\alpha \cdot k_{t}^{\alpha-1} \\
& \omega_{t}=(1-\alpha) A_{t} \cdot k_{t}^{\alpha}
\end{aligned}
$$

Furthermore, consumers maximise their utility, which yields the following equations:

$$
\begin{aligned}
& c_{1, t}^{i}=\frac{V_{t}^{i}}{R_{t+2}(1+\beta)} \\
& c_{2, t}^{i}=\frac{\beta V_{t}^{i}}{1+\beta}
\end{aligned}
$$

Finally, individuals must maximise the present value of their income. Individuals enrol in education if and only if the value of lifetime income for educated individuals is equal to or larger than the value of the lifetime income for unskilled individuals who start to work immediately. If the lifetime income is strictly larger for educated individuals, then everybody enrols. Hence, in the partial education regime, if some but not all individuals are enrolled, the following equality must hold:

$$
V_{t}^{e}=V_{t}^{n}
$$

For every cohort $t$, the lifetime value of income can be computed for educated and unskilled individuals by plugging Equations (16) and (17) into Equation (4). Equating the income values of unskilled and educated individuals, solving for $k_{t+2}$ and scaling one year yields the equation of the equilibrium in the "education market":

$$
k_{t+1}=\frac{\alpha}{\mu d_{t}} k_{t}^{\alpha}
$$

Equation (21) can be interpreted as the law of motion for the ratio of physical to human capital during the partial education regime. Equations (16), (17), and (21) determine the whole path for $R_{t}$, $\omega_{t}$ and, consequently, $V_{t}{ }^{i}$. The latter value, for both categories, must be equal to:

$$
V_{t}^{i}=\mu(1-\alpha) A_{t+1}{ }^{(\gamma+\sigma) \varphi+1} k_{t+2}^{\alpha}
$$

Once the paths for $V_{t}^{i}$ and $R_{t}$ are determined, it is possible to compute individual and aggregate consumption. Using Equations (18) and (19), aggregate consumption is given by: 


$$
c_{t}=\frac{V_{t-1}^{i} / R_{t+1}^{i}+\beta V_{t-2}^{i}}{1+\beta}
$$

Hence, the paths of $k_{t}, R_{t}, \omega_{t}, C_{t}$ are determined for a given initial value of $k_{t}$. The investment path for a given period $\tau$ is determined by choosing the levels of the stocks $\bar{K}_{\tau}$ and $\bar{H}_{\tau}$. This determines $Y_{\tau}$, but also $k_{\tau}$ and, as a consequence, $k_{t}$ for any $t$. Since the aggregate consumption is also determined, it is possible to determine the aggregate savings, the physical capital stock in the next period, and (since $k_{t}$ is determined for every $t$ ) the human capital stock in the next period. This procedure can then be repeated to calculate the values of stocks and output for all periods of the partial education regime.

This means that the level of $\bar{H}_{\tau}$ and $\bar{K}_{\tau}$ is sufficient information for determining all successive outcomes in terms of capital stocks and aggregate output and, in particular, to determine the growth rate of output per capita. This does not mean, of course, that the enrolment rates do not influence the growth rate of output per capita, as they influence it through the stock of human capital. It means that, once the human capital stock is known, knowledge of the enrolment rates is not necessary to determine the growth rate. Thus, two economies with the same stocks $\bar{H}_{\tau}$ and $\bar{K}_{\tau}$ will grow at the same rate (in terms of total or per capita output) in the partial education regime, despite possibly displaying different paths for the enrolment rate. In other words, two economies may have the same output growth rate but different enrolment growth rates. This is due to the fact that one economy at time $t$ could be characterised by higher levels of both past and recent enrolment rates, compensating the long-run positive effect on growth due to high enrolment rates in $t-2$ with the medium-run negative effect on growth due to high enrolment rates at $t-1 .^{9}$

This is the result of the fact that, in an equilibrium in which enrolment is between 0 and 1 , the growth of $k_{t}$ (the ratio between physical and human capital) is determined independently of the enrolment rates. In turn, the path of other variables such as the individuals' value of life-time income and aggregate consumption are determined by $k_{t}$. The result can be obtained by combining Equations (7), (21), (22) and (23) to derive $H_{t+1}$ as a function of $H_{t}$ :

9. Corresponding to a number of empirical papers on economic growth which use growth in GDP per worker as the dependent variable, it is interesting to derive the growth rate of output per worker as a function of the growth in the enrolment rate for two economies with the same human and physical capital stocks. Given that in the model the population is constant and equal to 3, per worker GDP growth is given by:

$$
\text { growth }_{Y p w, t}=\frac{Y_{t}}{Y_{t-1}} \cdot \frac{3-q_{t-1}}{3-q_{t}}
$$

In order to derive the effect of the enrolment rate growth , $q_{t} / q_{t-1}$ on growth in GDP per worker it is necessary to substitute the equilibrium rate $q_{t}$ with a function of $q_{t-1}$, given $H_{t}$. For the sake of brevity, the computations are not reported in this paper. However, it can be shown that an increase in the enrolment rate leads to a lower growth of GDP per capita, under the condition that the human capital stock is lower than it would be without enrolments. 


$$
H_{t+1}=\frac{d_{t}}{\alpha} H_{t}+\frac{(1-\alpha) d_{t} h_{2, t}^{e}}{(1+\beta) \alpha}\left(\beta+\frac{\mu^{\varphi(\sigma+\gamma)}}{d_{t-1}}\right)
$$

From this equation it is apparent that, in the partial education regime, every pair of values $\left\{q_{t-1}, q_{t-2}\right\}$ yielding the same value for $H_{t}$, also leads to the same path of future human capital stocks. Given the definition of $k_{t}$ and the aggregate production function, it is possible to determine every level of human and physical capital stock (and the corresponding level of output) without knowing the enrolment rates through Equations (21) and (24). ${ }^{10}$

The steady state is defined as an equilibrium in which $k_{t}$ and $q_{t}$ are constant. However, in our model the incentives to learn increase continuously as long as $\varphi>0$. Intuitively, this leads to $q_{t}=1$, if $t$ is large enough. This is indeed one of the results of the model (see Appendix A), which is consistent with the increase in human capital investments commented upon by Jones and Romer (2010).

The fact that the enrolment rate is equal to 1 when $t$ is large enough allows us to compute the steady state growth rate. Once $q_{t}$ is equal to $1, H_{t}$ becomes a function of $A_{t}$ only. It is then possible to obtain the following equation for the growth of human capital:

$$
H_{t+1}=\mu^{(\gamma+\sigma) \varphi} H_{t}
$$

Hence, the expression $A_{t} H_{t}$ grows every period at a rate equal to $\mu^{[(\gamma+\sigma) \varphi+1]-1}$. The model is thus similar to the standard Solow model with a constant population, and technology growing at a constant rate of $\mu^{[(\gamma+\sigma) \varphi+1]-1}-k_{t}$ converges to a constant level, and output grows at the same rate of $\mu^{[(\gamma+\sigma) \varphi+1]-1}$. This growth rate is equal to 1 plus the product of the parameter for technological growth $(\mu)$ and the growth that technological improvement induces on human capital with constant education $\left(\mu^{(\gamma+\sigma) \varphi}\right)$. Notice that the quality of education, represented by the parameter $\gamma$, positively affects the steady-state growth rate. This reflects that better education allows workers to cope better with technological change.

\section{Simulation}

This Section illustrates some implications of the model in a hypothetical economy starting with a situation of no school enrolment, and eventually reaching a steady state in which all individuals enrol in education. The baseline case of no government intervention is analysed first. The series obtained

10. This result rests on the assumption of homogeneous individuals. When we would relax this assumption, solving the model analytically becomes more complicated. Numerical simulations, not reported in this paper, show that the main implications of the model (i.e. rising enrolment rates with time and a different medium-term and long-term effect of education on GDP) are robust to different ways of introducing individual heterogeneity. 
for the relevant variables are then compared to the series obtained in two extreme cases: one in which the economy does not have the option to increase enrolment above 0 (so that education does not occur); and one in which the government enforces a policy of compulsory education for everyone.

In order to describe the different types of equilibrium of this model, it is useful to define (following de la Croix and Michel, 2002, Chapter 3) the discounted value of the marginal productivity of a unit of human capital $\left(z_{t}\right)$ :

$$
z_{t} \equiv \frac{\omega_{t}}{\omega_{t-1} R_{t}}=\frac{\mu}{\alpha} \frac{k_{t}}{k_{t-1}{ }^{\alpha}}
$$

In the baseline case of no government intervention, the value of this variable determines which equilibrium the economy will be in. In a competitive equilibrium, the condition for the enrolment to be equal to zero is that, given that nobody goes to school, every individual maximises the value of her life-time income by not going to school. This condition is the same as Equation (21), but expressed as an inequality:

$$
z_{t}<\frac{1}{d_{t-1}}
$$

In contrast, the condition for the enrolment rate to be equal to one is that, given that everybody goes to school, every individual maximises the value of her life-time income by going to school .

$$
z_{t+1}>\frac{1}{d_{t-1}}
$$

The equation that determines $z_{t}$ depends on the equilibrium the economy finds itself in. The path followed by this variable in the no education regime, in the partial education regime and in the universal education regime is given by:

$$
\begin{aligned}
& z_{t}=\frac{\mu^{-\sigma \varphi}\left[(\alpha+\beta) \mu^{\sigma \varphi}+(1+\alpha \beta)\left(1+\mu^{\varphi}\right)^{\sigma}\right]}{\alpha(1+\beta) \mu^{\sigma \varphi}+(1+\alpha \beta)\left(1+\mu^{\varphi}\right)^{\sigma}}+\frac{(-1+\alpha) \beta \mu^{-\sigma \varphi}}{\left[\alpha(1+\beta) \mu^{\sigma \varphi}+(1+\alpha \beta)\left(1+\mu^{\varphi}\right)^{\sigma}\right] z_{t-1}} \\
& z_{t}=\frac{1}{d_{t-1}} \\
& z_{t}=\mu^{-(\sigma+\gamma) \varphi}
\end{aligned}
$$

respectively.

Between each pair of these equilibria, there is one period of transition in which $z_{t}$ takes particular values. These values are reported in Appendix B. 
In the hypothetical case in which the economy does not have the option to expand enrolment, $z_{t}$ evolves only according to Equation (29) and, for $t \rightarrow \infty$, it converges to:

$$
z_{t}^{a n c *}=\mu^{-\sigma \varphi}
$$

In the case of compulsory education, we choose the period in which full enrolment is enforced so that it coincides with the first period of positive enrolment in the baseline case. This makes the comparison between the different cases easier, because all the three economies are identical until the enrolment starts to grow in the baseline case. With compulsory education, the equilibrium of the economy passes from the no education regime to the universal education regime, skipping the intermediary phase of the partial education regime. Between the two phases there are two transition periods with particular values of $z_{t}$, which is shown in Appendix B.

The parameters chosen for simulating the model are reported in Table 1. We assume that one period in the model corresponds to 15 years. In each period there are three cohorts which are either in education or in the labour market. For $\alpha, \mu$, and $\beta$ we choose values similar to those frequently used in the literature (notice that the annual values of $\beta$ and $\mu$ are equal to $1.03^{11}$ and 0.98 , respectively). The values of $a$ and $A_{0}$ (the initial value of technology) are set equal to 1 and 20, respectively. These values change the value of $t$ at which enrolments pick up and at which our comparison between the three alternatives starts, but leave the conclusions identical.

In the literature, there are no estimates of the parameters $\varphi, \gamma$ and $\sigma$. We therefore choose a triplet which fulfils two conditions. First, the value of $\varphi \cdot \gamma$ is implied by the growth of the wage premium of educated over unskilled individuals. In this model, the wage premium at time $t$ is equal to ${ }^{12}$ :

$$
w_{t}^{+} \equiv \frac{h_{2, t-2}^{e}}{h_{2, t-2}^{n}}=\frac{\mu^{\varphi(\sigma+\gamma)}}{\left(1+\mu^{\varphi}\right)^{\sigma}}\left(a A_{t-2}\right)^{\varphi \gamma}
$$

This gives an short expression for the log ratio of the wage premium in two subsequent periods, which can be used to obtain the first condition:

$$
\varphi \gamma=\frac{\ln \left(\frac{w_{t}^{+}}{w_{t-1}^{+}}\right)}{\ln \mu}
$$

11. This is equal to the steady-state growth rate commonly assumed in the literature (see e.g. Prescott, 1997).

12. Notice that the wage premium depends not only on the quality-of-education parameter $\gamma$, but also on other macroeconomic factors like the level of technology and the parameter for technological change $\mu$. This is different from the Lucas (1988) model, where the wage premium is proportional to the parameter representing the ability of education to raise productivity. The fact that other factors influence the wage premium is consistent with casual evidence, as the wage premium in countries that rank better in comparative assessments of pupils does not tend to be higher than in countries ranking worse in these assessments (see Banerjee and Duflo, 2005 for data on the wage premium across countries; see OECD, 2005 for data on international assessments of competencies of 8th-grade students). 
Goldin and Katz (2008, pp. 379-381) report estimates of the wage premium for different educational categories over time in the US. Based on their computations, we compute the value of the numerator of the previous expression. We use the college-versus-high school wage premium as higher education is the educational level in which enrolment rates are rising fastest in the US. We use the growth of the wage premium between 1990 and 2005, and the value of $\mu$ given in Table 1 . The resulting value for $\varphi \cdot \gamma$ is 0.2 . We choose values for $\varphi$ and $\gamma$ which are consistent with this condition. Choosing different values changes the numerical results, but not the qualitative conclusions drawn from the simulation, as it is shown in the sensitivity analysis of this section.

Second, we impose non-increasing returns to experience, or: $\sigma+\gamma \leq 1$. However, since productivity can only change once every 15 -year period, returns to experience must be very large to produce a substantial increase of earnings during the career cycle. Hence, $\sigma$ is chosen in order to satisfy the condition $\sigma+\gamma=1$. The chosen triplet of parameters is $\varphi=0.4, \gamma=0.5, \sigma=0.5$.

Table 1 Parameter values used in the simulation

\begin{tabular}{cccccc}
\hline Parameter & Value & Parameter & Value & Parameter & Value \\
$\alpha$ & 0.35 & $\mu$ & 1.56 & $\sigma$ & 0.5 \\
$\beta$ & 0.74 & $\varphi$ & 0.4 & $\gamma$ & 0.5 \\
\hline
\end{tabular}

Figure 3 illustrates the development of the enrolment rates obtained by simulating the baseline case and the two alternatives: no education and compulsory education. The enrolment rates implied by the different policies are shown in Figure 3. In both the baseline case and the compulsory education case enrolment is equal to 0 in period 2. In the latter case, full enrolment is enforced in period 3, whereas in the baseline case it is only reached in period 6 . 


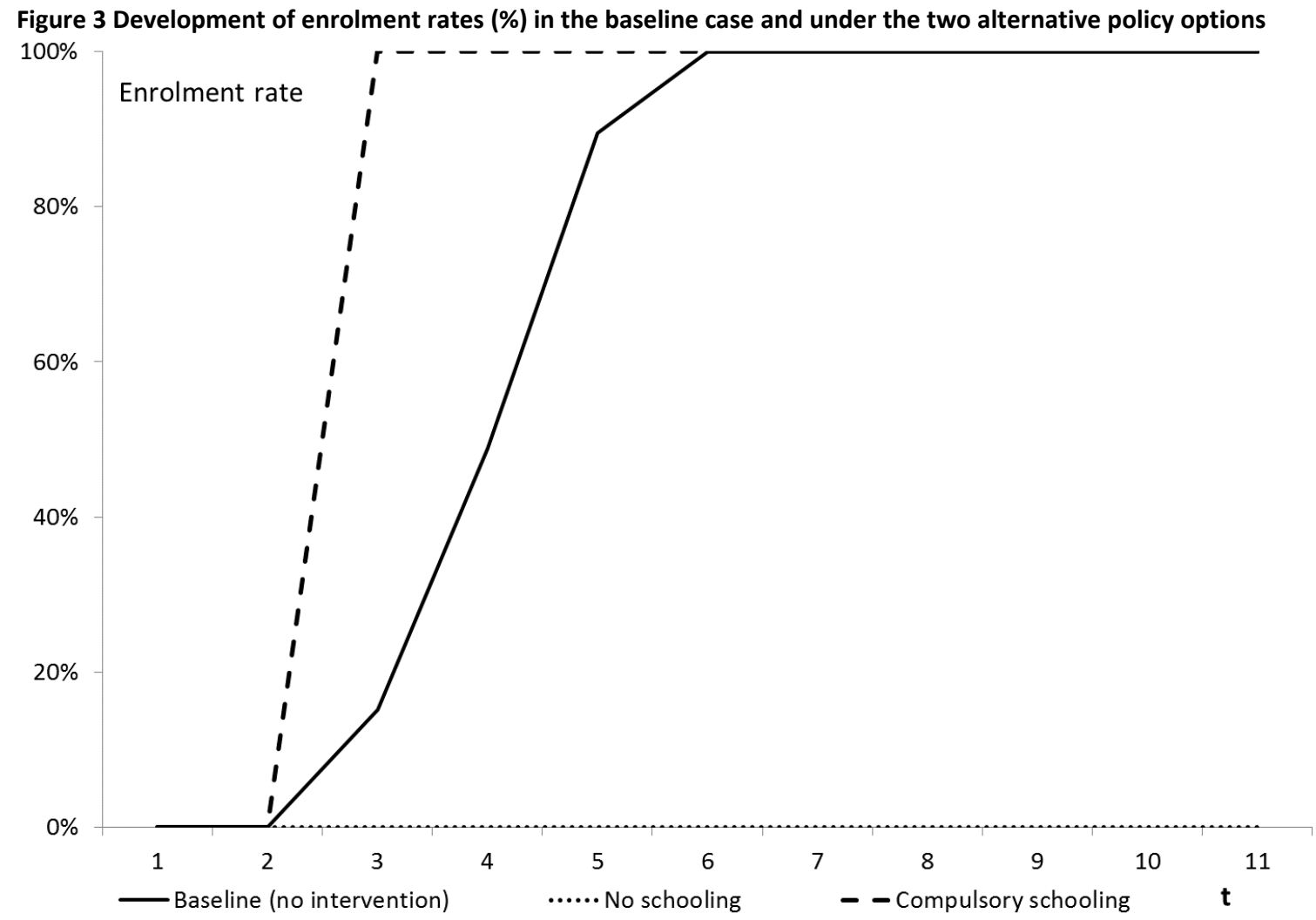

Figure 4 Development of the GDP per capita growth rate (\%) in the baseline case and under the two alternative policy options

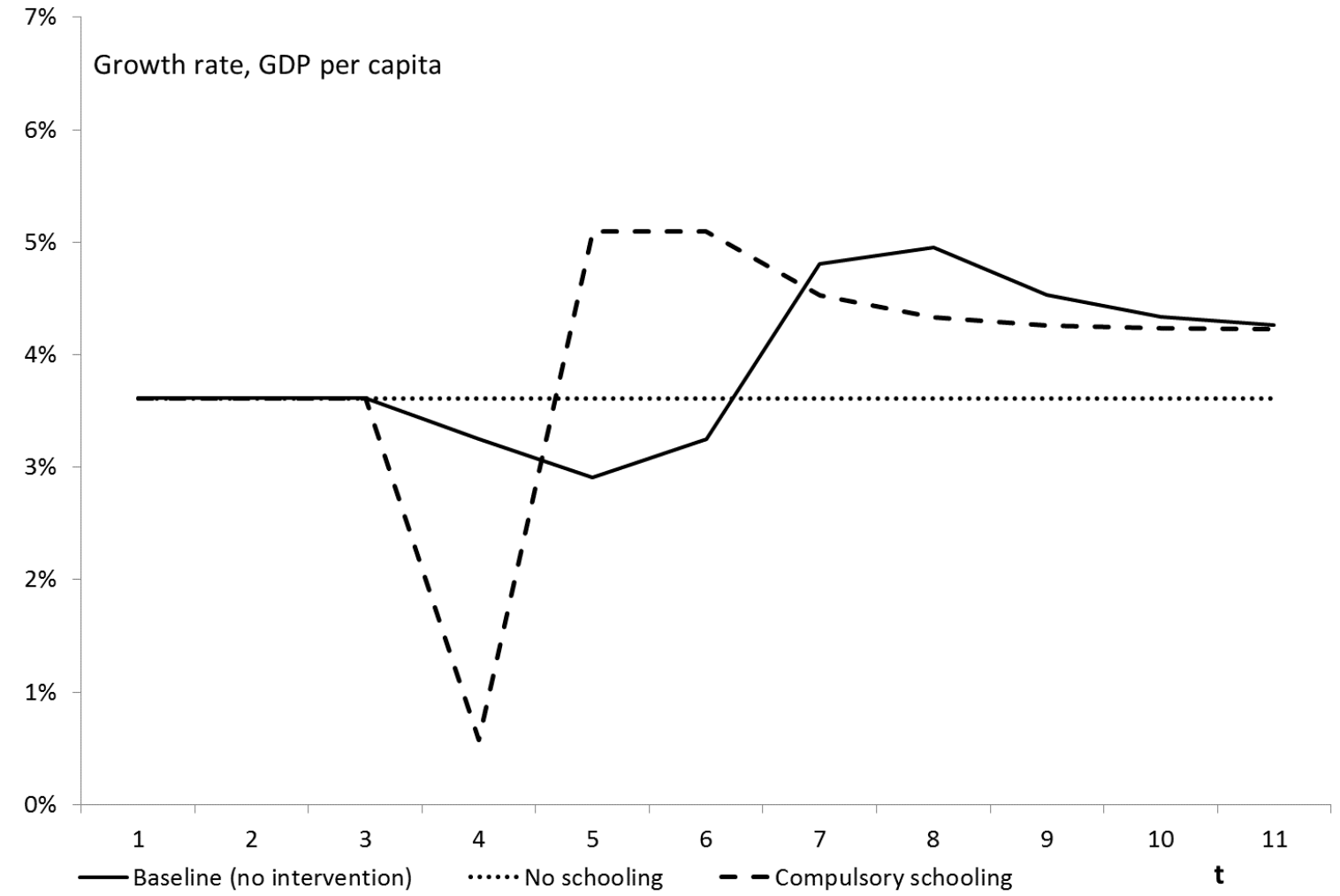


Figure 4 shows the development of GDP growth per capita in the baseline case as well as under the two alternative educational policies. In the no-education case the economy is at the steady state with a growth rate of $3.6 \%$. In the baseline case, economic growth first slows down to $2.9 \%$ in period 5 , because of the medium-term loss in human capital due to the increase in the enrolment rate. Then the growth rate recovers up to $5 \%$ in period 8 . In this baseline case, the growth rate is particularly high just after the period in which the economy reaches full enrolment, when the level of education cannot increase (avoiding the medium-term negative effect of education on GDP), but the economy still experiences the positive, long-term effect of the increase in the level of education of the past generations. Eventually, the economy reaches the new steady-state level, in which GDP per capita grows at a higher rate $(4.2 \%)$ than with no education. The development of the economy with compulsory education is similar to the baseline case, but the variations in GDP growth are more pronounced. GDP per capita growth first drops to a very low rate of $0.6 \%$ in period 4 , and then recovers at a faster rate than in the baseline case. Figure 4 clearly shows the medium-term negative effect and the long-term positive effect of enrolments on GDP per capita which is predicted by the model: GDP per capita is highest in the no-education case until period 6, but it converges to a higher level in the baseline case and with compulsory education.

The different medium- and long-term implications of the baseline case and the two alternatives suggest that governments could choose different educational policies depending on how they weigh the welfare of current and future generations. To show this, we define the following welfare function:

$$
W=\sum_{t=0}^{\infty} \Pi^{t} \cdot U_{t}^{i}
$$

where $U_{t}{ }^{i}$ is equal to the lifetime utility of unskilled individuals in the no education regime, educated individuals in the universal education regime, and any of the two types in the partial education regime (as in the latter regime, $U_{t} e^{e}=U_{t} u$ ); $\Pi$ is a parameter which determines a government's time preference, and it is equal to the difference between 1 and the yearly discount rate, $\pi$, to the power of 15 (remember that in our simulation one period corresponds to 15 years). From the three alternative cases, the government would prefer the one yielding the maximum value for $W$.

Figure 5 displays the total utility enjoyed by every generation. The utility $U_{t}{ }^{i}$ follows a linear growth trajectory in the no education case, from which it deviates in the other two cases. If there is compulsory education, the utility is higher than in the no education case for the generation born in period 2, just before full enrolment is enforced. The reason is that enrolments of the younger cohort (born in period 3) reduces the size of the human capital endowment of the economy in period 4, raising the salary per unit of human capital (hence, the life-time income) of the individuals born in 
period 2. Conversely, the medium-term reduction in GDP per capita caused by compulsory education (see Figure 4) translates in a reduction of consumption for the following cohorts, so that individuals born in periods 3 and 4 enjoy less utility than in the no education case. Finally, because of the longterm positive effect of education on GDP per capita (see Figure 4) and consumption, generations born after period 4 enjoy a higher utility than in the no education case. Utility in the baseline case follows a similar pattern as in the compulsory education case, but the deviations from the linear trend of the no education case are less pronounced.

Given the parameters used in the simulation, for reasonable values of the annual discount rate, the absence of government intervention is preferred to the alternatives. However, if the yearly discount rate is extremely high $(\pi>0.82)$ or extremely low $(\pi<-0.010$, implying that future generations' utility receives more consideration than current generations'), the government prefers the compulsory education policy. Given the parameters used here, the no-education alternative is never preferred.

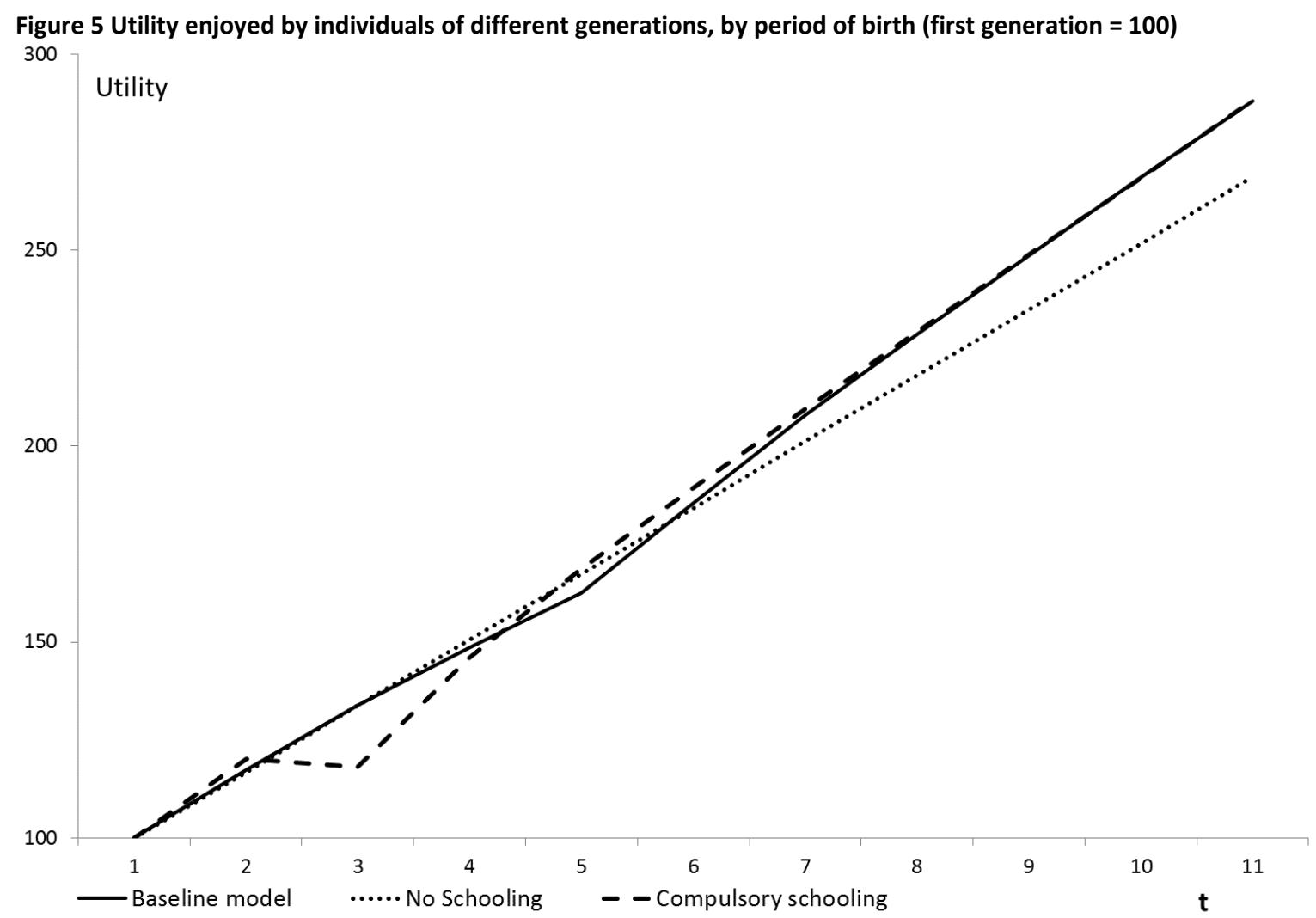

To see how the conclusions of the previous paragraphs are sensitive to different choices of the triplet of parameters $\{\phi, \gamma, \sigma\}$, we show how the model economy develops in four different scenarios. The first scenario is the same as the benchmark case that we have just discussed, with the difference that education is of higher quality $(\gamma=0.75)$. This scenario helps to understand the role of the quality of education in the model. The second scenario is designed in such a way that, any point in time, 
experience plays a less important role for determining productivity than in the other scenarios. Compared to the benchmark scenario, this is reflected both in a lower value of $\gamma$ and $\sigma$ (which are both set equal to 0.33 ), meaning that the returns to experience are lower at any given point in time; and in a lower value of $\varphi$ than in the benchmark scenario (0.2), indicating that it matters less whether work experience is accumulated in more technologically advanced environments. The third and fourth scenario illustrate the opposite case: experience matters more for productivity at any given point in time. In both scenarios, both $\varphi$ and the sum of $\gamma$ and $\sigma$ are twice as big as in the benchmark case. However, while in the third scenario $\gamma$ is left unchanged (0.5) and $\sigma$ is increased (1.5), in the fourth scenario the reverse is true. Hence, in the fourth scenario the role played by schooling in the returns to experience is much larger. Table 2 shows the parameters chosen for the different scenarios.

Table 2 Parameter values chosen for the alternative scenarios

$\begin{array}{cccc}\text { Scenario } & \varphi & \gamma & \sigma \\ \text { Benchmark } & 0.4 & 0.5 & 0.5 \\ \text { Scenario 1 } & 0.4 & 0.75 & 0.5 \\ \text { Scenario 2 } & 0.2 & 0.33 & 0.33 \\ \text { Scenario 3 } & 0.8 & 0.5 & 1.5 \\ \text { Scenario 4 } & 0.8 & 1.5 & 0.5\end{array}$

Figure 6 shows the development of the enrolment rates in the alternative scenarios. Changes in the parameters of the model lead to differences in both, the time period at which the economy leaves the no education regime and the number of additional periods necessary to reach the universal education regime. Enrolments first start to grow in Scenario 4, where the values for $\varphi$ and $\gamma$ are large, and the incentives to undertake education are strong. In this scenario, the enrolment rate moves from 0 to 1 in only two periods. In contrast, in Scenario 2, where the values for $\varphi$ and $\gamma$ are the smallest, individuals start to enrol exactly 26 periods later, and it takes 5 additional periods before every individual is enrolled.

Figure 7 presents the development of the GDP per capita growth rate in the case of no government intervention (baseline case) in the alternative scenarios. Since we are most interested in how economic growth evolves following an increase in the enrolment rate, we aligned the series along the time period $\tau$, in which the economy leaves the no education regime. For example, $\tau$ is equal to 3 for the Benchmark Scenario, and to 21 for Scenario 2. In all cases, it is apparent that growth in GDP 
Figure 6 Enrolment rates in the alternative scenarios

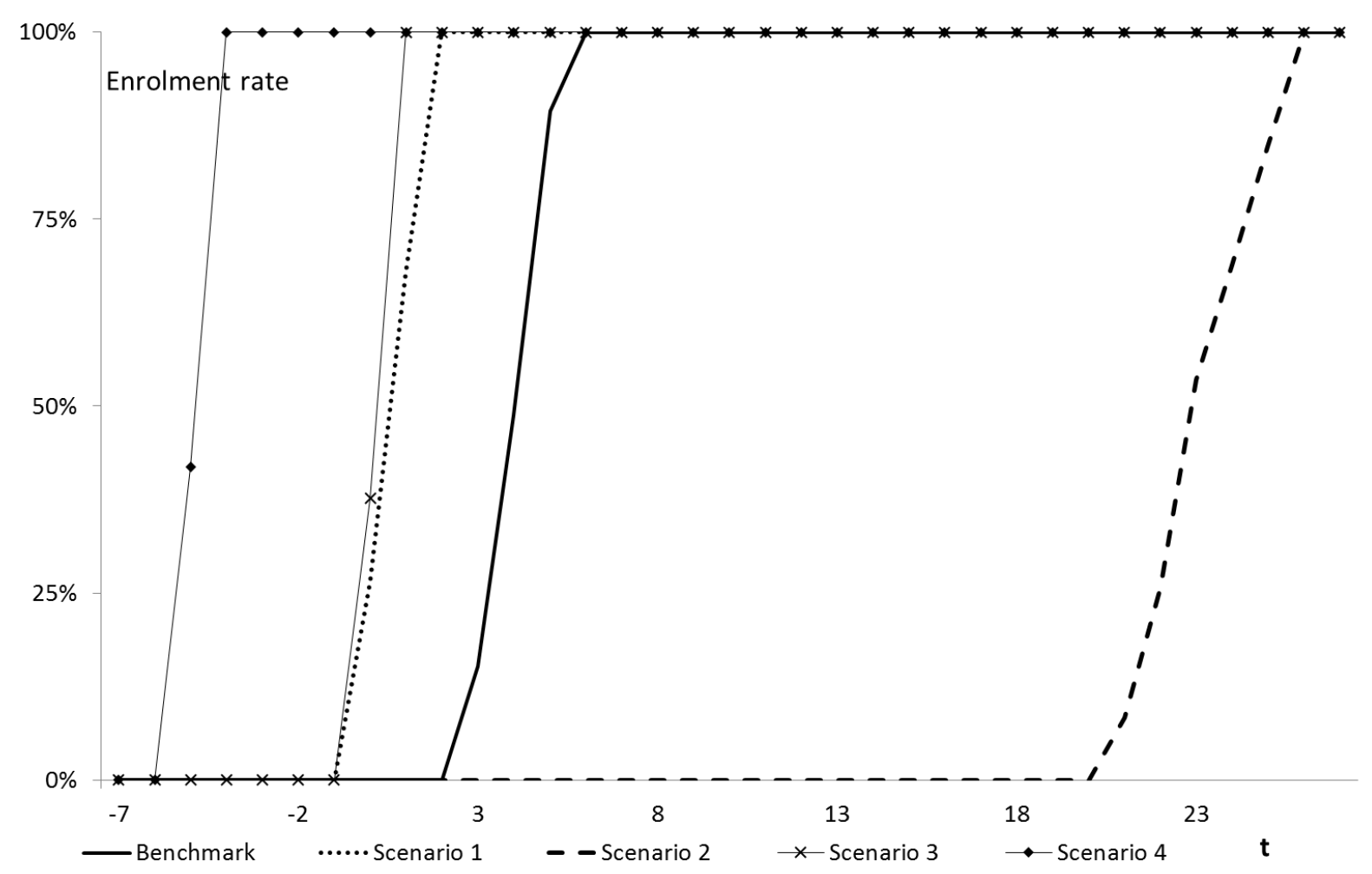

Figure 7 Development of the GDP per capita growth rate (\%) in the alternative scenarios in absence of government intervention (baseline case)

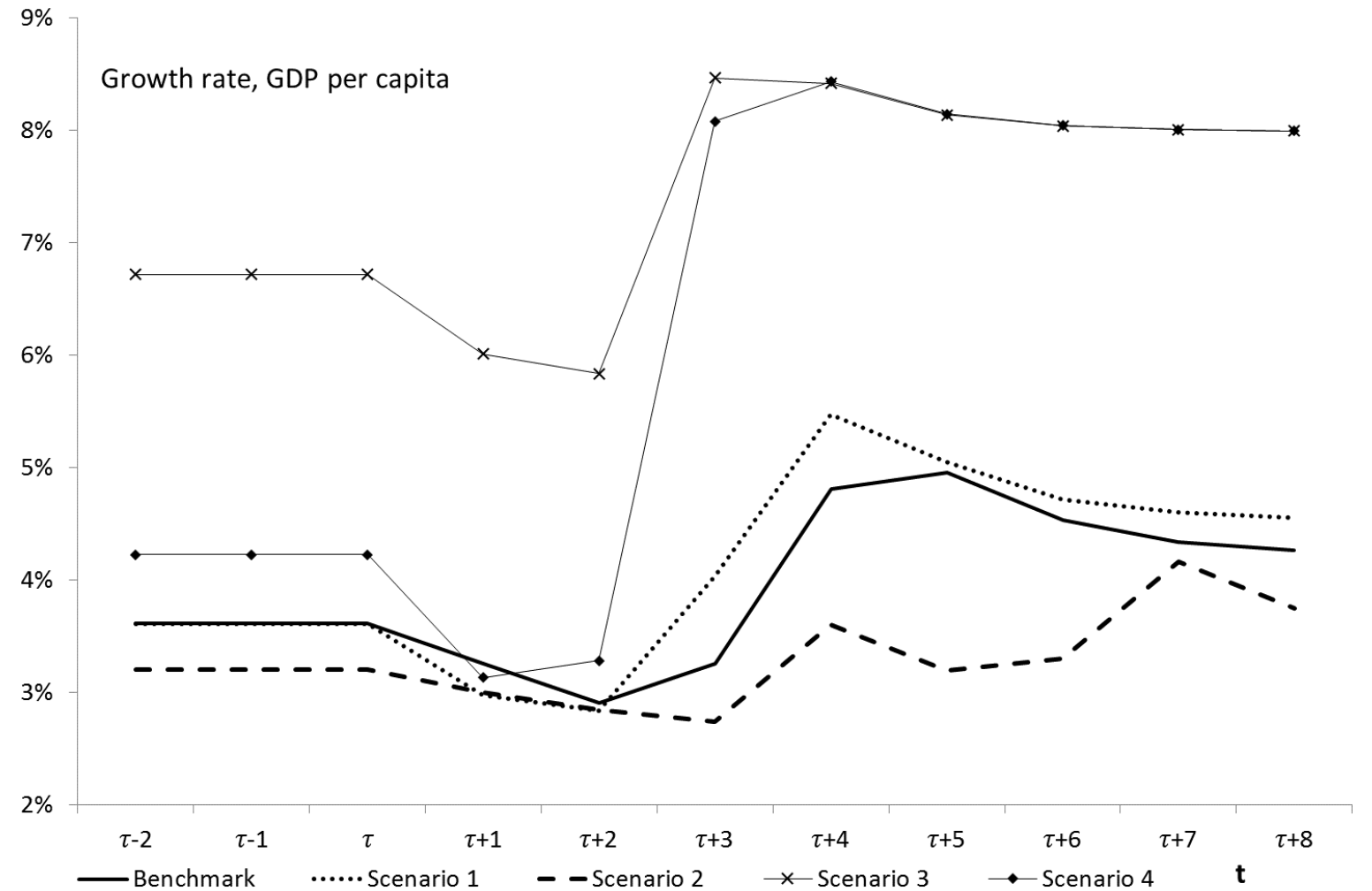


per capita falls after $\tau$. After some periods, however, the growth rate increases again, and eventually it stabilises at a higher level than before $\tau$. Economic growth follows a very specific pattern in Scenario 2 (in which the partial education regime lasts the longest), with several peaks and troughs. The two scenarios with large returns to experience (i.e. Scenarios 3 and 4) converge towards the same steady-state growth rate for large $t$, which is the highest among all scenarios. This confirms that large returns to experience imply high rates of economic growth in the steady state of this model.

The comparison between the benchmark scenario and Scenario 1 is of particular interest, as the latter is characterised by the same parameter values as the benchmark, with the exception of a larger value for $\gamma$, representing the quality of education. However, Figure 6 shows that the change in this parameter affects other variables of the model, such as the enrolment rates, and the type of equilibrium in which the economy finds itself at a given point in time. Hence, it is difficult to understand which part of the change in the growth rates shown in Figure 7 is due to the change in the parameter $\gamma$ and which part is due to changes in other variables of the model. The two scenarios can be compared better in Figure 8, which illustrates the evolution of the GDP per capita growth rate if the government enforces compulsory education. The compulsory education policy offers the advantage that there are no parameters-induced differences in the progression of the enrolment rates. Comparability among different scenarios is further enhanced by the assumption that the policy is always enforced in the same period $(t=3)$. In general, Figure 8 shows that in all the five scenarios, economic growth displays the typical pattern seen in Figure 4. This consists of a fall in economic growth, followed by a recovery (particularly pronounced in Scenario 5, in which $\gamma$ takes on the largest value) and by the stabilisation at a new growth rate which exceeds the growth rate preceding the enforcement of compulsory education.

This pattern is visible also in Scenario 1 and in the benchmark scenario. In period 4, the growth rate is at a low of $0.6 \%$ in both scenarios. However, the economy recovers faster in Scenario 1 (in which the quality of education is better), as the growth rate is equal to $7.1 \%$ in period 5 , compared to $5.1 \%$ for the benchmark scenario. Subsequently, the growth rate converges towards a higher steady state level in Scenario 1 than in the benchmark scenario (4.5\% against $4.2 \%)$. Hence, the change in the quality of education leads to the same fall of output following the enforcement of the compulsory education policy, but to a higher growth rate afterwards. 


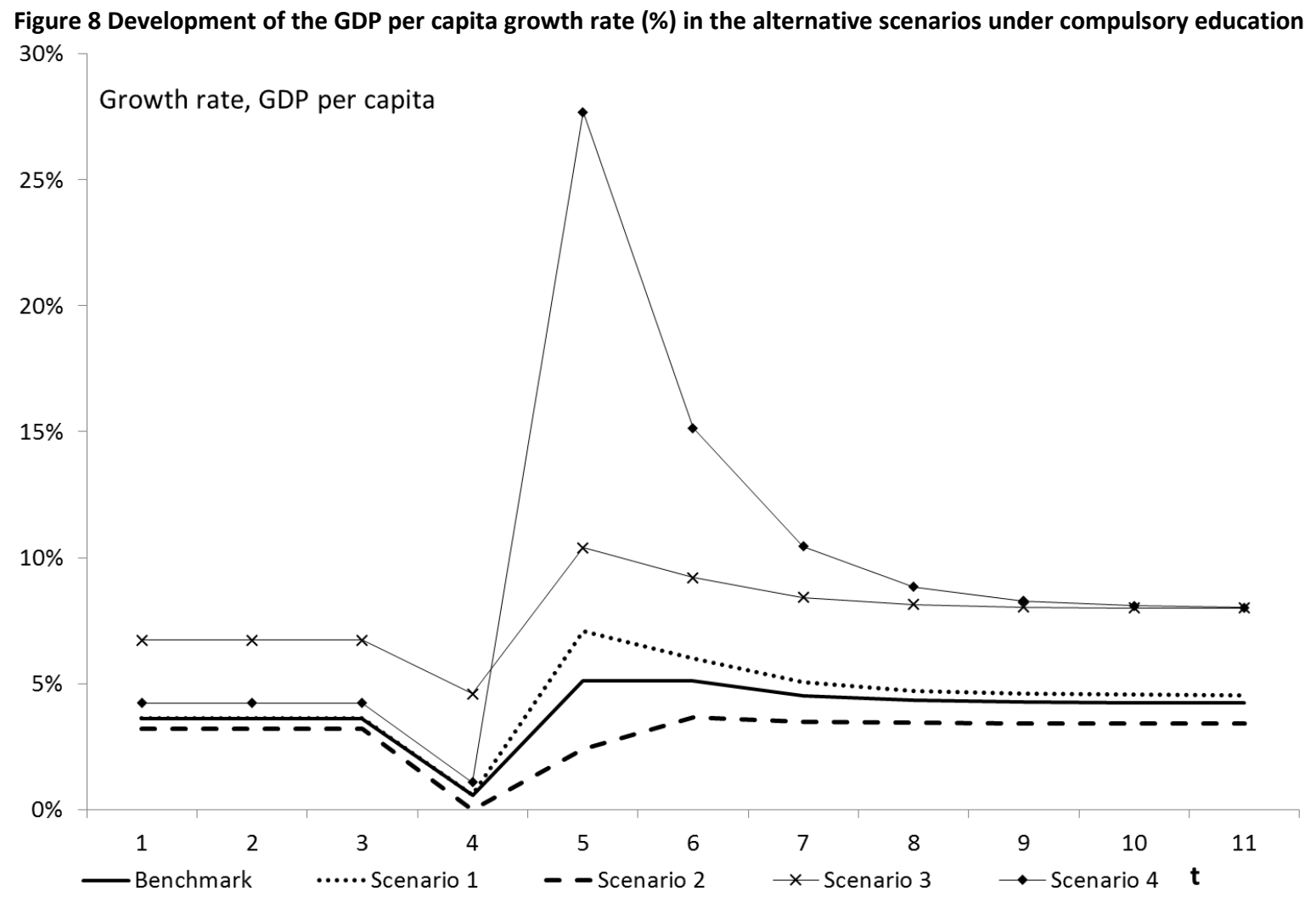

Finally, we consider the government's choice of different policies in the alternative scenarios. In almost all scenarios, no intervention (the baseline course of action) is preferred over the other policy options for reasonable values of the yearly discount rate $\pi$. However, there is one exception: in Scenario 2, the one with the longest duration of the partial education regime, the government's preferred option is the compulsory education policy, as long as the discount parameter is lower than $1.5 \%$. This exception is very interesting, as it shows that there exist combinations of the parameters such that forward-looking governments should push enrolment. Of course, this does not mean that (even for these combinations of parameters) compulsory education can be Pareto efficient, as the individuals of some cohorts would experience a net loss of utility.

\section{Conclusions}

The model we developed in this paper enables us to explain the insignificant empirical results found in the macroeconomic literature on the relationship between education and economic growth. Our model builds on the assumption that education does not contribute to individual productivity from the moment graduates start working. Education is assumed to increase workers' ability for learning by doing. At the aggregate level, this translates into a medium-term negative effect of the share of young individuals enrolled in education on economic growth. However, the long-term effect of the enrolment rate to education on economic growth is positive, because education increases the rate of 
learning with experience. Simulations with this model show that the effect of a rise in the enrolment rate on economic growth is ambiguous, because it depends on the level of both past and recent educational enrolment rates.

In our model, a clear distinction is made between the quality (as represented by the parameter $\gamma$ ) and the quantity (as represented by the educational enrolment rate $q$ ) of education. Improving the quality of education has the potential to raise the rate of economic growth without a trade-off between the medium- and long-term economic performance.

The model matches various macroeconomic stylised facts on educational investments: the substantial positive correlation between the quality of education and economic growth (Hanushek and Woessmann, 2012); the secular rise in human capital investments (Jones \& Romer, 2010); and the absence of a positive correlation between the returns to education and the quantity of education. The main implication of the model is that expanding the share of young individuals enrolled in education can be a painful investment for governments which primarily focus on the next elections. In the medium term, investing in education has a negative impact on economic growth, even though the effect of education on growth turns positive in the long run. This implication is illustrated by simulating three alternative courses of action for a hypothetical government (no education, compulsory education and no intervention). The absence of government intervention policy is preferred to the other courses of action for reasonable values of the rate at which the government discounts the utility of future generations, although a compulsory education policy is preferred if the government is more concerned about future generations' wealth than the wealth of current generations. 


\section{References:}

Alchian, A. (1963). Reliability of Progress Curves in Airframe Production. Econometrica, 31, 679-693.

Almalaurea. (2011). Condizione Occupazionale dei Laureati - XIII Indagine 2010. Bologna.

Arrow, K. (1962). The Economic Implications of Learning by Doing. American Economic Review, 29, 155-173.

Banerjee, A. V., and Duflo, E. (2005). Growth Theory through the Lens of Development Economics. In P. Aghion \& S. N. Durlauf (Eds.), Handbook of Economic Growth (Vol. 1, pp. 473-552). Amsterdam: Elsevier.

Benhabib, J., and Spiegel, M. M. (1994). The Role of Human Capital in Economic Development: Evidence from Aggregate Cross-country Data. Journal of Monetary Economics.

Benhabib, J., and Spiegel, M. M. (2005). Human Capital and Technology Diffusion. In Handbook of Economic Growth (Vol. 1, pp. 936-965).

Brunello, G. (2001). On the Complementarity between Education and Training in Europe (No. 309). Bonn.

Cardoso, A. R., Guimarães, P., and Varejão, J. (2011). Are Older Workers Worthy of Their Pay? An Empirical Investigation of Age-Productivity and Age-Wage Nexuses. De Economist, 159, 95-111.

Ciriani, S. (2007). Education policy in a general equilibrium model with heterogeneous agents. Economic Bulletin, 9, 1-7.

Cohen, D., and Soto, M. (2007). Growth and Human Capital: Good Data, Good Results. Journal of Economic Growth.

Curs, B., Bhandari, B., and Steiger, C. (2011). The Roles of Public Higher Education Expenditure and the Privatization of the Higher Education on U.S. States Economic Growth. Journal of Education Finance, 36.

De la Croix, D. (2001). Growth Dynamics and Education Spending: The Role of Inherited Tastes and Abilities. European Economic Review, 45, 1415-1438.

De la Croix, D., and Michel, P. (2002). Dynamics and Policy in Overlapping Generations. Cambridge: Cambridge University Press.

Dostie, B. (2011). Wages, Productivity and Aging. De Economist, 159, 139-158.

Frazis, H. J., and Herz, D. E. (1995). Employer-provided Training : Results from a New Survey. Monthly Labor Review, 118, 3-17. 
Goldin, C., and Katz, L. F. (2008). The Race Between Education and Technology. The Race between Education and Technology: (Vol. 12984). Cambridge: Harvard University Press.

Hanushek, E. a., and Woessmann, L. (2012). Do Better Schools Lead to more Growth? Cognitive Skills, Economic Outcomes, and Causation. Journal of Economic Growth, 17, 267-321.

Hellerstein, J. K., and Neumark, D. (1995). Are Earnings Profiles Steeper than Productivity Profiles ? Evidence from Israeli Firm-Level Data. Journal of Human Resources, 30, 89-112.

Jones, C. (1995). R\&D-based Models of Economic Growth. Journal of Political Economy, 103, 759-784.

Jones, C. I., and Romer, P. M. (2010). The New Kaldor Facts: Ideas, Institutions, Population, and Human Capital. American Economic Journal: Macroeconomics.

Jovanovic, B., and Nyarko, Y. (1996). Learning by Doing and the Choice of Technology. Econometrica, 64, pp. 1299-1310.

Krueger, A. B., and Lindahl, M. (2001). Education for Growth: Why and for Whom? Journal of Economic Literature.

Lazear, E. P. (1979). Why Is There Mandatory Retirement? Journal of Political Economy.

Lucas, R. E. (1988). On the Mechanics of Economic Development. Journal of Monetary Economics.

Nelson, R. R., and Phelps, E. S. (1966). Investment in Humans, Technological Diffusion, and Economic Growth. The American Economic Review, 56, 69 - 75.

OECD. (2005). Education at a Glance 2005. Paris: OECD.

Pecchenino, R. A., and Utendorf, K. R. (1999). Social security, social welfare and the aging population. Journal of Population Economics, 12, 607-623.

Ponthiere, G. (2011). Asymptotic Age Structures And Intergenerational Trade. Metroeconomica, 62, 175-217.

Pritchett, L. (2001). Where Has all the Education Gone? The World Bank Economic Review, $15,367-391$.

Pritchett, L. (2006). Does Learning to Add up Add up? The Returns to Schooling in Aggregate Data. In Handbook of the Economics of Education (Vol. Volume 1, pp. 635695).

Psacharopoulos, G., and Patrinos, H. A. (2004). Returns to investment in education: a further update. Education Economics, 12, 111-134. 
Rogers, M. L. (2008). Directly Unproductive Schooling: How Country Characteristics Affect the Impact of Schooling on Growth. European Economic Review, 52, 356-385.

Rosenzweig, M. R. (1995). Why Are There Returns to Schooling ? American Economic Review, 85, 153-158.

Simon, J. L., and Steinmann, G. (1984). The Economic Implications of Learning-by-doing for Population Size and Growth. European Economic Review, 26, 167-185.

Temple, J. R. W. (1999). A positive effect of human capital on growth. Economics Letters, $65,131-134$.

Thurow, L. C. (1982). The Failure of Education as an Economic Strategy. The American Economic Review, 72, 72-76.

Torvik, R. (2001). Learning by Doing and the Dutch Disease. European Economic Review, 45, 285-306.

Welch, F. (1970). Education in Production. Journal of Political Economy, 78, 35-59.

Yellen, J. L. (1984). Efficiency Wage Models of Unemployment. American Economic Review, 74, 200-205.

Zon, A. van, and Antonietti, R. (2005). Education and Training in a Model of Endogenous Growth with Creative Destruction (No. 11). 


\section{Appendix A}

Suppose to have an economy in the partial education regime, characterised by a series of enrolment rates $\left\{q_{t}, q_{t+1}, q_{t+2}, \ldots\right\}$, where $q_{s}<1$ for every $s=t, t+1, t+2, \ldots$

For the economy to be in equilibrium, Equation (30) must hold for every $s$. From the definition of $k_{t}$ and Equation (7), it follows that:

$$
\text { (A1) } \quad k_{t}=\frac{Y_{t-1}-C_{t-1}}{A_{t} H_{t}}
$$

Then, Equation (30) implies that:

$$
\text { (A2) } \frac{\mu}{\alpha} \frac{k_{t}}{k_{t-1}^{\alpha}}=\frac{H_{t-1}-C_{t-1}}{\alpha H_{t}}=\frac{1}{d_{t-1}}
$$

where $\mathcal{C}_{t} \equiv C_{t} /\left(A_{t} \cdot k_{t}^{\alpha}\right)$. From substituting Equation (A2) into Equations (8) and (23), we can derive the following Equation:

$$
\begin{aligned}
& \text { (A3) } \frac{\alpha \mu^{\varphi \sigma}}{d_{t-2}} q_{t-1}+(1-\alpha) q_{t-2}+\frac{d_{t-2}}{\mu^{\varphi \sigma}} q_{t-3}= \\
& \quad=\left[1+\left(1+\mu^{\varphi}\right)^{\sigma}\right]\left(\frac{d_{t-1}}{\alpha \mu^{\varphi \sigma}}-1\right)+\beta \frac{h_{2, t-2}^{e}}{h_{2, t-2}^{n}}+\frac{1-\alpha}{(1+\beta) \mu^{\varphi \gamma}} \frac{h_{2, t-1}^{e}}{h_{2, t-1}^{e}-h_{2, t-1}^{n}}
\end{aligned}
$$

If $q_{t+1}, q_{t+2}$, and $q_{t+3}$ are held constant, the term on the right-hand side of the Equation (A3) increases faster than the term on the left-hand side. Hence, for the condition to hold, the enrolment rates must increase with time ${ }^{13}$. Since the enrolment rates are bounded as they cannot exceed 1 , for $t$ large enough, the right-hand side will exceed the left-hand side. This implies that at some point in time, it will necessarily be the case that:

$$
\text { (A4) } \frac{\mu}{\alpha} \frac{k_{t}}{k_{t-1}^{\alpha}}=\frac{H_{t-1}-C_{t-1}}{\alpha H_{t}}>\frac{1}{d_{t-1}}
$$

Which is Equation (28), i.e. the sufficient condition for all individuals to enrol in education.

13. Notice that the left-hand side is increasing for all the enrolment rates. 


\section{Appendix B}

In Appendix A, the following equality was derived:

(B1) $\quad z_{t}=\frac{H_{t-1}-C_{t-1}}{\alpha H_{t}}$

This is the formula used for computing $z_{t}$ in each equilibrium and transition phase. $z_{t}$ is then determined by: consumption at time $t-1$, which is in turn determined by the life-time value of the income of the generations of individuals born at times $t-2$ and $t-3$, and the human capital stocks at times $t$ and $t-1$, which in turn are determined by $q_{t-1}, q_{t-2}$ and $q_{t-3}$.

This implies that, between the no education regime and the partial education regime, there is a transition phase in which $z_{t}$ is determined in the same way as in the no education regime, with the difference that $q_{t-1}>0$. Between the partial education regime and the universal education regime there is also a transition phase. In this transition phase $z_{t}$ is determined in the same way as in the universal education regime, with the difference that $q_{t-3}<1$. The formulas for $z_{t}$ in the two transition phases described before are (respectively):

$$
\begin{aligned}
& \text { (B2) } \quad z_{t}=\frac{\mu z_{t-1}\left[(\alpha+\beta) h_{1, t-2}^{u}+(1+\alpha \beta) h_{2, t-3}^{u}\right]-(1-\alpha) \alpha \beta h_{1, t-3}^{u}}{\mu z_{t-1}\left[(1+\alpha \beta) h_{2, t-2}^{u}+\alpha(1+\beta) h_{1, t-1}^{u}\left(1-q_{t-1}\right)\right]} \\
& \text { (B3) } \quad z_{t}=\frac{(1+\beta) h_{2, t-1}^{u}\left(1-q_{t-3}\right)+h_{2, t-1}^{e}\left[(1+\beta) q_{t-3}-(1-\alpha) \beta\right]}{(1+\alpha \beta) h_{2, t-2}^{e}}
\end{aligned}
$$

If the government enforces compulsory education for everyone, there are two main historical periods: the no education regime and the universal education regime. Inbetween, there are two transition periods. In the first one, $z_{t}$ is computed as in the no education regime case, with the difference that $q_{t-1}$ is equal to 1 ; in the second one, $z_{t}$ is derived in the same way as in the universal education regime, with the difference that $q_{t-3}=0$. The formulas are identical to the two above, with the difference that $q_{t-1}$ must be replaced with 1 and $q_{t-3}$ with 0 . 